\title{
Hacia una ecología política de las nuevas periferias urbanas: suelo, agua y poder en Santiago de Chile ${ }^{1}$
}

\section{Towards a political ecology of the new urban peripheries: land, water and power relations in Santiago de Chile}

\author{
Michael Lukas² (D) Maria Christina Fragkou³ (D) y Alexis Vásquez ${ }^{4}$ (D)
}

\begin{abstract}
RESUMEN
Durante las últimas décadas la provincia de Chacabuco, en el norte de Santiago, se ha transformado profundamente en términos territoriales debido a la instalación de megaproyectos urbanos para segmentos sociales acomodados, en contextos que hasta ese entonces eran eminentemente rurales. Desde la ecología política suburbana analizamos las distintas estrategias económicas, políticas y metabólicas con vista a los recursos del agua y el suelo a través de las cuales grandes grupos económicos-financieros, apoyados por el Estado, han producido un paisaje desigual de archipiélagos. Los métodos utilizados en este trabajo incluyen revisión de prensa, entrevistas en profundidad con actores privados, estatales, y comunitarios, y un análisis de los registros de derechos de agua en la oficina de Conservador de Bienes Raíces en la provincia de Chacabuco. En términos empíricos y conceptuales, demostramos que la producción de la nueva periferia urbana y sus patrones de fragmentación socioterritorial y ambiental no son resultados de fuerzas abstractas de globalización, sino de acciones deliberadas de comodificación, concentración (de derechos de propiedad) y financiarización de recursos naturales como el suelo $y$ el agua.
\end{abstract}

Palabras claves: fragmentación, paisaje de archipiélagos, ecología política suburbana, financiarización, desigualdad.

\begin{abstract}
During the last decades, the province of Chacabuco, in the north of Santiago, has been profoundly territorially transformed due to the installation of urban mega-projects for well-off social segments in contexts that until then were eminently rural. From the perspective of suburban political ecology, we analyze the different economic, political and metabolic strategies with view to the water and land resources through which large economic-financial groups, supported by the state, have produced an unequal landscape of archipelagos. The methods used in this work include press review, semi-structured with private, public, and community actors, and an analysis of water rights records in the office of Real Estate Curator in the province of Chacabuco. In empirical and conceptual terms, we demonstrate that the production of the new urban periphery and its patterns of socioterritorial and environmental fragmentation are not the result of abstract forces of globalization, but of deliberate actions of commodification, concentration (of property rights) and financialization of natural resources like land and water.
\end{abstract}

Key words: fragmentation, archipelagos landscape, suburban political ecology, financialization, inequality.

Elaborado en el marco del Proyecto Fondecyt de Iniciación 11150789. Ingreso: 02-01-2018 / Aceptado: 26-06-2020

Departamento de Geografía, Facultad de Arquitectura y Urbanismo, Universidad de Chile. Correo electrónico: mlukas@uchilefau.cl. ORCID:0000-0001-5749-5073

Departamento de Geografía, Facultad de Arquitectura y Urbanismo, Universidad de Chile. Correo electrónico: mariac.fragkou@uchilefau.cl. ORCID : 0000-0001-6831-4549

Departamento de Geografía, Facultad de Arquitectura y Urbanismo, Universidad de Chile. Correo electrónico: alexvasq@u.uchile.cl. ORCl- 
En América Latina, como en otras partes del mundo, las periferias urbanas son hoy día espacios de altísimo dinamismo económico, político y social. Especificando el visionario planteamiento de Lefebvre (2003) sobre la revolución urbana y el devenir hacia una "sociedad completamente urbana", Keil (2013: 9 y 2018) indica que se trata en esencia de una "revolución suburbana", es decir, la combinación de un incremento global de la población en áreas urbanas no centrales, el incremento de actividad económica y la expansión urbana en términos espaciales. Evidentemente, las formas en que se da esta expansión urbana alrededor del mundo ha cambiado de forma significativa en las últimas décadas. En América Latina, hasta los años setenta y ochenta las periferias urbanas se construyeron, sobre todo, en el contexto de las grandes migraciones del campo a la ciudad a través de la toma de terrenos, loteos ilegales para la autoconstrucción y la producción estatal de grandes conjuntos de vivienda social, proceso que Caldeira (2017) ha llamado "urbanización periférica". Si bien estos modos de producción socioespacial y de hábitat siguen existiendo (Abramo, 2012), hace algunas décadas las periferias urbanas se han transformado en un pináculo de la penetración del capital financiero, muy vinculado a procesos más globales de neoliberalización y financiarización. Tal vez la máxima expresión de este hecho es la instalación, en las nuevas periferias urbanas en América Latina y en otros lados del Sur global (Shatkin, 2008, Wissink, 2013), de extensos y complejos sistemas de infraestructuras hipermodernas tales como amplias redes de autopistas, parques industriales y tecnológicos, aeropuertos, barrios cerrados, megaproyectos urbanos integrados y ciudades privadas.

En una primera ola de estudios sobre la ciudad latinoamericana los nuevos patrones de expansión y crecimiento han sido descritos como parte de un giro desde la ciudad polarizada hacia la ciudad fragmentada, producto de procesos de globalización y privatización (Janoschka, 2002; Borsdorf et al., 2007). La fragmentación de los espacios urbanos y sus periferias en América Latina en estos trabajos era vista como un efecto casi automático de procesos macroestructurales de globalización (Ciccolella, 1999). Como respuesta a autores que criticaban el carácter "meramente descriptivo" de dichos trabajos (Crot, 2006: 229), en una segunda ola de estudios se ha analizado cómo en la práctica y en contextos específicos se producen las nuevas territorialidades y con qué consecuencias. En estos trabajos se indaga en aspectos de economía política, de toma de decisiones y procesos de gobernanza para establecer el enlace teórico empírico entre macroprocesos como la globalización y procesos de transformación territorial a nivel regional y local (Crot, 2006; Cuenya y Corral, 2011; Abramo, 2012; Lukas, 2014; Reis, 2014; entre otros).

Aunque parece evidente que las transformaciones territoriales en su esencia son procesos socioambientales que implican la movilización y metabolización de recursos naturales a gran escala, con efectos desiguales sobre distintos grupos sociales, esta cuestión ambiental hasta el momento ha quedado afuera de la discusión, excepto por unos pocos trabajos (Castro, 2005; Romero y Vásquez, 2006; Naranjo, 2007; Fernández et al., 2010; Nicolas-Artero, 2015; Guibrunet et al. 2017). Es en este contexto que aquí proponemos una lectura desde la ecología política urbana de la producción de las nuevas periferias urbanas, la cual corresponde a un campo conceptual emergente en el contexto latinoamericano. En línea con los objetivos generales de la ecología política buscamos desfetichizar las nuevas periferias urbanas como efectos casi automáticos de fuerzas abstractas como la globalización, y poner actores, instituciones, y relaciones de poder en el centro del análisis, develando cómo en el caso de Santiago las constantes interacciones entre estas producen nuevas socionaturalezas que benefician a algunos y perjudican a otros (Swyngedouw y Heynen, 2003). 
Figura 1. Las comunas de Til Til, Colina, y Lampa, de la Provincia de Chacabuco, en la Región Metropolitana de Santiago

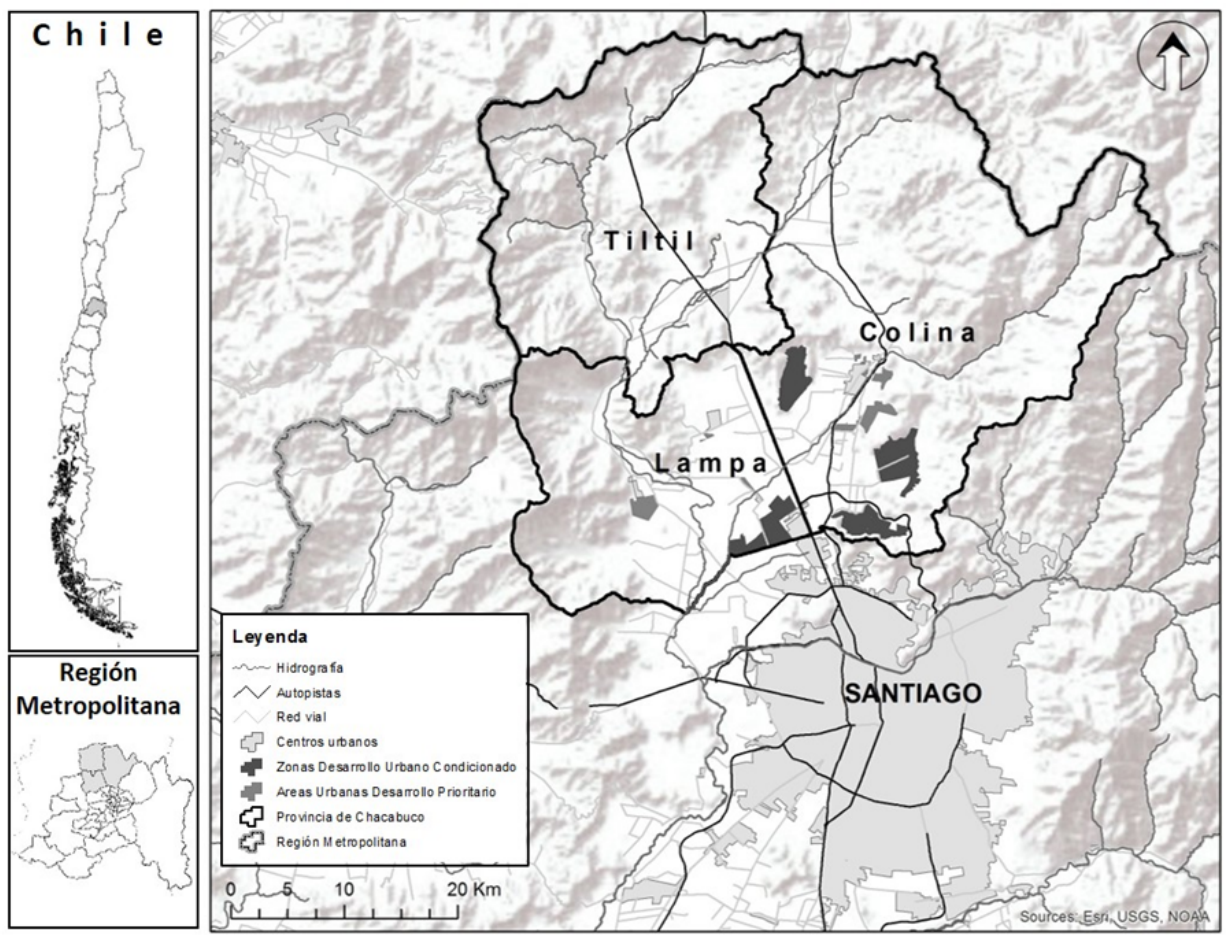

Santiago es un caso de estudio interesante porque en las últimas dos décadas ha mostrado formas y patrones de crecimiento urbano que se desvían mucho de las formas tradicionales. Lo novedoso de este crecimiento periférico es que procede a través de grandes proyectos inmobiliarios para hasta 70.000 habitantes -llamados megaproyectos, ciudades privadas, ciudades valladas o privatópolis - al estilo del nuevo urbanismo (Hidalgo et al., 2008; Lukas, 2014). "Combinando un máximo grado de planificación con un máximo grado de especulación", los megaproyectos son en la práctica "paisajes empaquetados" (Knox, 2008), expresión de un "urbanismo de enclave" (Wissink, 2013), iniciados y desarrollados desde el sector privado, dedicados a las clases medias y altas y que vienen con toda la infraestructura y los servicios urbanos incluidos - autopistas, shopping malls, colegios, universidades y clínicas. Además, estos cuentan con un gran número de amenidades como son lagunas artificiales, vastos espacios verdes, canchas de golf y polo. La mayor concentración de estos proyectos se ve en la Provincia de Chacabuco en la zona norte de la ciudad, especialmente en las comunas de Lampa y Colina (Figura 1). De hecho, Chacabuco en la última década ha mostrado una de las cifras más altas de crecimiento poblacional, de infraestructura, y de desarrollo inmobiliario de la Región Metropolitana de Santiago (Salazar, 2007; Heinrichs et al., 2011; De Mattos et al., 2014). ${ }^{5}$

"Una de cada 4 casas del segmento alto, sobre las 6.000 UF, que se comercializa en la Región Metropolitana se vende en Chicureo, cifra que confirma que este barrio es la extensión del sector oriente de la capital. La zona muestra las más altas tasas de crecimiento de la Región Metropolitana. Proyecta 120.000 nuevos habitantes para la próxima década, que se sumarán a los 30.000 vecinos que residen en la zona. En 2010 se comercializaron unas 600 viviendas, y desde el 2012 se mantiene la venta de cerca de 1.200 unidades anuales. También proyecta una inversión de US\$3.000 millones hacia 2018, con un desarrollo de la infraestructura y equipamiento: supermercados, strip centers, centros de salud y colegios. Asimismo, es la principal reserva de suelo para el segmento medio y alto que queda en Santiago" (Publimetro, 12 de agosto 2014). 
Lo que buscamos es comprender, a partir del análisis del caso de Chacabuco, la producción de las nuevas periferias desde la ecología política urbana, a través de su análisis como un proceso intrínsecamente socioambiental, metabólico, y desigual. Más específicamente, demostramos que la producción de la nueva periferia urbana y sus patrones de fragmentación socioterritorial y ambiental no son resultados de fuerzas abstractas de globalización, sino de acciones deliberadas de comodificación, concentración (de derechos de propiedad) y financiarización de recursos naturales como el suelo y el agua, implementadas con un rol fundamental del Estado, pero que en última instancia corresponden a estrategias de inversión, circulación y acumulación de capital de algunos de los grupos económicos y financieros más importantes del país. Con eso contribuimos, por un lado, a expandir el conocimiento sobre el rol de las periferias urbanas en la actual fase urbana del capitalismo global en la línea de Keil $(2013,2018)$ o Arboleda $(2016)$, con su énfasis en los aspectos metabólicos. Por el otro lado, nuestro trabajo contribuye a una discusión más local sobre la economía política de las transformaciones urbanas contemporáneas en la Región Metropolitana de Santiago. Mientras especialmente López $(2013,2016)$ a través de una serie de investigaciones ha demostrado el carácter políticamente dirigido y socialmente excluyente de la renovación urbana de Santiago, constatando la producción de una nueva geografía social metropolitana, estos trabajos hasta el momento no han considerado las dimensiones ambientales y metabólicas. Además, argumentamos que para comprender la real escala de la reestructuración urbana desigual y con carácter de clase a través de la cooperación pública-privada en el marco del urbanismo pro-empresarial, correctamente descrita en los trabajos mencionados sobre la gentrificación de los peri-centros, es necesario levantar la mirada hacia las periferias expandidas junto a los actores, estrategias y procesos metabólicos ahí presentes.

En el siguiente apartado se presentan los principales conceptos y teorías de la ecología política urbana y del agua, que nos ayudan a examinar e interpretar los procesos de producción de las nuevas periferias de las ciudades latinoamericanas. Luego, se describe la aplicación y evolución del modelo neoliberal en Chile, haciendo énfasis en los procesos de comodificación y privatización del suelo y del agua. Finalmente, presentamos cómo y con qué consecuencias se han desarrollado estos procesos en la provincia de Chacabuco. Los métodos utilizados en este trabajo incluyen revisión de prensa, entrevistas semi-estructuradas con actores privados, estatales, y comunitarios, y un análisis de los registros de derechos de agua en la oficina de Conservador de Bienes Raíces en la provincia de Chacabuco. En el cierre del artículo se discuten las principales conclusiones de la investigación.

\section{Conceptualizando la producción de nuevas periferias urbanas: la ecología política de la urbanización y del agua en América Latina}

La ecología política urbana (EPU) es un campo interdisciplinario que hace énfasis en "el análisis de las relaciones de poder que dan lugar a una determinada distribución de los servicios medioambientales y de los recursos naturales" en espacios urbanos (Domene, 2006: 173). Sobre todo en sus inicios muy influenciada por la geografía marxista, para la EPU, sociedad y naturaleza se relacionan dialécticamente por lo que el proceso de urbanización por definición es un proceso socioambiental. De forma similar, se aplica una combinación dialéctica entre la consideración 
de procesos macroeconómicos y estructurales y microespecificidades en lugares concretos, es decir una mirada multiescalar. Desde este punto de vista, la urbanización se entiende como un proceso metabólico que depende y moviliza recursos naturales - como suelo y agua, entre otros - y a la vez los integra a la circulación del capital y lleva a la producción de ambientes urbanos desiguales (Zimmer, 2010). Se argumenta que los flujos metabólicos urbanos reflejan y, de hecho, se constituyen a través de relaciones de poder (Swyngedouw y Heynen, 2003) y que la organización social de estos flujos crea condiciones socioambientales desiguales para los habitantes urbanos (Heynen et al. 2006). En este sentido, estos espacios urbanos o periurbanos ambientalmente desiguales - como las nuevas periferias urbanas de América Latina - son resultado de la forma específica en que se organiza la relación entre flujos de capital, recursos naturales y relaciones de poder en distintas escalas y en contextos específicos (Swyngedouw y Heynen, 2003, Castán Broto et al., 2012).

En los últimos años ha habido un intenso proceso de reflexión sobre el estado del arte de la EPU, sus fortalezas y debilidades en términos conceptuales, metodológicos y empíricos. Por un lado, se ha destacado que la EPU efectivamente ha cubierto un vacío en las investigaciones de ecología política, ya que ésta ha tenido un enfoque eminentemente rural (Zimmer, 2010). Por otro lado, y en el marco de recientes debates sobre la urbanización planetaria, han aparecido críticas al "ciudadismo metodológico" (methodological cityism), haciendo llamados por una EPU que no solo analice ciudades en sus límites administrativos sino más bien el proceso de urbanización, generalizado, y sus procesos metabólicos en distintas escalas, más allá de las ciudades consolidadas (Angelo y Wachsmuth, 2014; Swyngedouw y Kaika, 2014; Arboleda, 2015a y 2015b, 2016). Mientras muchos autores en este contexto se refieren a lo que se entiende por urbanización extendida y los paisajes operacionales del capitalismo urbano-financiero, incluyendo a megainfraestructuras de generación eléctrica, recintos mineros y paisajes de la agroindustria (Arboleda, 2016), nosotros argumentamos que hace falta tratar una territorialidad particular que ha sido poco estudiada y hasta invisibilizada en la ecología política, es decir, hay que estudiar la nueva periferia urbana en el marco de una ecología política suburbana o periurbana (Keil, 2018: 6; McKinnon et al., 2017).

Una rama dentro de la ecología política que en este contexto es de particular utilidad por su atención a procesos de urbanización, son los trabajos que tratan los temas de gestión y privatización del agua (Bakker 2003). Budds (2012) plantea que "el manejo del agua no debe ser entendido meramente como la distribución del recurso entre los distintos usuarios, sino como una respuesta entre los actores sociales que luchan por controlar este recurso para garantizar sus propios intereses". Estudios fundacionales sobre la relación entre urbanización y agua han mostrado que la urbanización fomenta y necesita la industrialización y mercantilización del agua (Bakker, 2003). Mientras que en el Norte Global el acceso al agua en el marco de la urbanización ha sido universalizado, en el Sur Global este ideal no ha sido alcanzado (Pflieger, 2008). Dónde ha sido alcanzado, como paradójicamente ha sido el caso del Chile neoliberal, la capacidad de consumo se transforma en un elemento de desigualdad e injusticia (Durán, 2015).

Basándose en argumentos de una mayor eficiencia en la provisión de servicios, durante los años ochenta y noventa hubo, en Chile y otros países en desarrollo, importantes transformaciones institucionales asociadas a conceptos neoliberales de privatización y mercantilización del agua (y otros servicios como electricidad), y se vieron varias olas de privatización y la entrada de empresas multinacionales bajo distintos esquemas (Budds y McGranahan, 2003). Mientras esto 
ha tenido efectos positivos como la extensión de redes de distribución, también significó que el agua pasó de ser un bien público a ser una mercancía y que el control sobre el agua en parte importante ha sido traspasado a actores privados. Además, un efecto socioterritorial ha sido que "en la mayoría de las ciudades del sur las redes de provisión de agua potable no operan de forma homogénea sobre el paisaje urbano; se traslapan con y son penetrados por mecanismos alternativos de provisión de servicios" (Bakker, 2003). En nuestro caso de estudio eso tiene su expresión en la yuxtaposición entre megaproyectos inmobiliarios servidos por sanitarias internacionales, por un lado, y Comités de Agua Potable Rural que abastecen a la población rural tradicional, por el otro.

Para esta geografía desigual Bakker (2003) propone el concepto del "archipiélago" y que define como "islas de provisión en red, espacialmente separadas pero relacionadas". La geografía de archipiélagos al mismo tiempo es causa y efecto de tres procesos: "una creciente territorialización del poder corporativo, el encerramiento de los comunes hídricos y una creciente penetración de los intereses de las elites (mayoritariamente urbanas)" (ibid.). Esto apunta a que las empresas privadas transnacionales que se encargan de proveer a las poblaciones de las ciudades del sur Global por definición no lo hacen porque el acceso al agua es un derecho humano sino porque es o ha sido transformado en un negocio muy rentable, cada vez más penetrado por una lógica rentista y financiera (March y Purcell, 2014). Mientras más se enfoque el abastecimiento hacia sectores de alta capacidad de pago, evitando además donde sea posible la construcción de nuevas redes, mayor será la rentabilidad. De esta forma, (1) el agua es comodificada, es decir, se transforma en una mercancía, (2) tiene lugar un confinamiento de los comunes hídricos y (3) se desarrolla una focalización hacia las elites, demostrando que los flujos de agua son transformados por flujos de poder. Para Silveira (2007) estos territorios que se construyen a través de una apropiación selectiva de regiones o algunas de sus partes por grandes grupos económicos son "territorios corporativos", los territorios emblemáticos de la globalización.

Desde la ecología política, la comodificación y privatización tanto del agua como del suelo periurbano pueden ser considerados como estrategias paraestatales y publicas-privadas para dar paso a la entrada de grupos económicos-financieros nacionales y transnacionales, es decir, para la captura de rentas y la acumulación y circulación de capital. En este sentido, la fragmentación territorial y socioambiental no es resultado de fuerzas abstractas de un mercado global como sugiere el término de 'globalización', sino de estrategias deliberadas de actores específicos, tanto públicos como privados, que cada vez más están relacionados a actores, instituciones y lógicas del capital financiero, es decir, el proceso de financiarización, resultando en nuevos patrones de desarrollo geográfico desigual (Bakker, 2003; Harvey, 2011; Loftus y March, 2015; Ahlers y Merme, 2016).

En este sentido, los megaproyectos inmobiliaros emergen en las nuevas periferias urbanas a modo de archipiélagos (Bakker, 2003) de territorios corporativos en el sentido de Silveira (2007) pero a su vez como "nuevos espacios estatales", que resultan de la confluencia de intereses corporativos-financieros y de "estrategias espaciales estatales" (Brenner, 2003). Este último término hace énfasis en la "capacidad estatal de influir sobre las geografías de la acumulación" y las entiende "como intentos de moldear las geografías del desarrollo industrial, la inversión en infraestructura y las luchas políticas hacía un 'anclaje espacial' o una 'coherencia estructural' (Harvey, 1989)" (Brenner, 2003: 204).

Si estos archipiélagos son al mismo tiempo nuevos espacios estatales y territorios corporativos funcionales a la acumulación y circulación de capital, es importante comprender la forma 
en que el Estado llega a sus estrategias espaciales y su "selectividad estratégica" en promover algunas zonas y relegar otras (Brenner, 2003). En este contexto sirve apoyarse en Jessop (1990: 270, citado en Brenner, 2003: 202) quien plantea que "el Estado como tal no tiene poder - es meramente un ensamble institucional; solo tiene un juego de capacidades institucionales y responsabilidades que intermedien este poder; el poder del Estado es el poder de las fuerzas que actúan en y a través del Estado".

A continuación, demostraremos que en Chile las fuerzas que actúan en y a través del Estado han sido aquellas desplegadas por grandes grupos económicos-financieros. Estos grupos al mismo tiempo emergieron a través y jugaron roles claves tanto en el golpe militar como en la continuación del modelo neoliberal después del retorno a la democracia. Con vistas a la ecología política de la nueva periferia urbana neoliberal, este punto es clave porque han sido dichos actores los protagonistas tanto de la comodificación y privatización del suelo, del agua y de la expansión de la ciudad a través de megaproyectos. Bajo su influencia, Chacabuco se transformó en un paisaje de archipiélagos, en un territorio que es un reflejo de su poder y sus estrategias de inversión, especulación y acumulación.

\section{La instalación del modelo neoliberal en Chile: liberalización del suelo y privatización del agua}

\section{La instalación del modelo neoliberal}

Las constelaciones económicas y políticas alrededor de los años del golpe militar en Chile han sido bien documentadas y no existe duda de "que las reformas neoliberales no simplemente han sido el producto de ideología o experimentación (p.ej. Foxley, 1983) sino que más bien corresponden al resultado de estrategias políticas bien planificadas, bien maniobradas y también bien camufladas" (Huneeus, 2000 en Budds, 2013: 308). La batalla que hubo después del golpe entre distintos proyectos políticos la ganó la alianza entre el capital financiero y los llamados Chicago Boys, en desmedro de la antigua oligarquía agrícola y terrateniente. Mientras este último grupo abogaba por reformas moderadas, los grupos emergentes ligados al capital financiero y comercial en conjunto con los tecnócratas de Chicago empujaban por políticas radicales de (neo-) liberalización y una economía controlada por el sector privado, basada en un desarrollo centrado en la explotación de recursos naturales (Fischer 2011). Un elemento clave en el diseño del proyecto neoliberal en Chile ha sido la privatización de empresas públicas y así, durante la dictadura, entre 1973 y 1989, hubo dos olas importantes de privatización que cambiaron la composición de la clase empresarial dominante, lo que ha tenido efectos sobre los procesos del crecimiento urbano (Fischer, 2011).

En la primera ola de privatización, entre 1974 y 1982, fueron traspasadas 325 empresas públicas al sector privado donde los principales beneficiarios eran grandes grupos económicos nacionales (como Luksic, Matte, Angelini, Cruzat-Larraín). El hecho de que estas empresas fortalecieron su ya importante posición a través de las privatizaciones implicó una extrema concentración de la actividad económica y financiera, que desencadenó una severa crisis económica al inicio de los años ochenta (Fernandez Jilberto, 2004). Entre 1985 y 1989 se realizó la segunda ronda de privatizaciones. Según Fischer (2011) y Fernández Jilberto (2004) de esta ronda de privatizaciones hubo 
tres grupos de beneficiarios: (1) grandes grupos económicos como Matte, Angelini y Luksic, que profundizaron sus actividades en sectores estratégicos - muy dependientes del agua tales como la minería, el sector forestal y la agroindustria -, y que hasta el día de hoy son los más grandes del país; (2) empresas transnacionales que adquirieron empresas estatales a precios muy bajos; y (3) grupos económicos más pequeños y cercanos al régimen de Pinochet. Con vistas al último grupo mencionado destacan los tecnócratas neoliberales donde varios de los Chicago Boys se transformaron en empresarios constituyendo nuevos grupos económicos-financieros (Fernández Jilberto, 2004). Han sido especialmente estos nuevos grupos, en control de las principales instituciones y entidades financieras del país, que conformaron la nueva elite económica y política - en específico grupos como Hurtado Vicuña, ECSA, Penta y Fernández León - que de inmediato buscaron la entrada al negocio inmobiliario a gran escala, desarrollando conceptos para megaproyectos periurbanos y que presionaron de forma significativa por la liberación de suelo urbanizable en la provincia de Chacabuco (Moenckeberg, 2001; Lukas, 2014). Sus recursos de poder se basaban en el hecho de que estos grupos eran considerados como "poderes fácticos", es decir, como actores sin que su consentimiento a la Concertación (coalición política de centroizquierda) no le era posible gobernar (Fischer, 2011).

\section{La neoliberalización de las políticas urbanas, del agua, y la expansión de Santiago}

Con Budds (2013) se puede plantear que la privatización del agua era una pieza clave del proyecto neoliberal en Chile y lo mismo se puede decir de la política urbana y del suelo. Desde luego el agua y el suelo han sido de primordial importancia para industrias de extracción de recursos naturales y también lo han sido para los procesos de urbanización y el negocio inmobiliario, por ende, eran sectores estratégicos para el nuevo modelo de acumulación neoliberal. El año clave para el inicio de la neoliberalización tanto del suelo como del agua en Chile fue 1979. Con el objetivo de alinear estos sectores con los principios del libre mercado se empezó la revisión del Código de Aguas y se implementó una nueva Política Nacional de Desarrollo Urbano (PNDU).

En 1979 empezó una revisión al Código de Aguas, que posteriormente fue aprobada en 1981. Antes de esta fecha los servicios y usos del agua eran manejados directamente por el Estado, mediante un modelo de planificación centralizada, pero con la aplicación del Código de Aguas se (re-)introdujeron los derechos de agua "convirtiéndolos en propiedad privada para transferirlos del Estado a los usuarios, separando el agua de la tierra para convertirlo en mercancía para que pudiese tener precio y ser comercializado de forma independiente. Se argumentó que la privatización y comodificación iba a incrementar la seguridad hídrica, eficiencia y su valor productivo" (Bauer, 1997 y 1998a)" (Budds, 2013).

La nueva Política Nacional del Desarrollo Urbano de 1979, también marcó un claro giro conceptual y práctico con el pasado, declarando que "el suelo no es un recurso escaso" (MINVU, 1981). Bajo esta lógica, los mercados del suelo fueron liberados de restricciones e impuestos con el objetivo de apoyar la constitución de una industria inmobiliaria propiamente tal. La ciudad se debería expandir según las necesidades y lógicas del mercado, sin intervención estatal, es decir, sin planificación territorial. En este contexto, se modificó el Plan Intercomunal de Santiago que era el principal instrumento de planificación regional, cambiando 60.000 ha de uso rural a urbanizable (la superficie urbana en este momento era de 40.000 ha). Eso sí, el nuevo plan preveía dos 
tipos distintos de suelo urbanizable con vista a la provisión de infraestructura urbana (tales como las redes de agua): “i) una zona urbana en la cual la urbanización se autoriza y las autoridades públicas son obligadas a invertir para viabilizar los terrenos, equiparlos y suministrar un servicio público; ii) una zona de expansión urbana que autoriza la urbanización privada sin que el Estado se comprometa a construir las infraestructuras y a integrar las nuevas urbanizaciones en el nuevo perímetro urbano (Petermann, 2006: 218)" (Pflieger, 2008). Mientras la primera zona era limitada en términos de superficie y se restringía básicamente a la zona ya construida, la segunda zona era muy amplia e implicaba altos costos de urbanización debido a que los mismos desarrolladores inmobiliarios debían asumir la construcción de las redes de servicios, tales como las de agua potable. Según Pflieger (2008) han sido estos altos costos y la baja capacidad de financiamiento e inversión de la principal empresa pública de agua de Santiago los que frenaron la expansión urbana en esta época, demostrando el rol primordial que tienen las redes de agua para factibilizar la urbanización. De hecho, en estos años "el lobby inmobiliario" empezó a desarrollar "un papel determinante a favor del establecimiento de una agenda para una reforma profunda del sector sanitario, preparada en 1988 y validada en 1989, poco antes de la caída del Gobierno Militar" (Pflieger, 2008: 142).

En esta época hubo una importante excepción a la tendencia descrita anteriormente en el cuadrante noroeste de Santiago, donde asociado a un explosivo crecimiento del barrio alto se desarrolló un modelo de suministro de agua que luego se empleó en la urbanización y construcción de los "territorios corporativos" en Chacabuco. Primero para el suministro de parcelas de agrado y después para proyectos más grandes de urbanización, los desarrolladores inmobiliarios crearon sus propias empresas privadas de agua en las comunas Vitacura, Las Condes y Lo Barnechea (Empresa Agua Potable lo Castillo, Empresa de Agua Potable Los Dominicos y Aguas Manquehue). Este fue un primer antecedente de la instalación de "servicios cesionarios" (Graham y Marvin 2001) especiales y privatizados para las nuevas zonas urbanas de clases altas, mientras el resto de la zona urbana de la Región Metropolitana era suministrada por las empresas públicas EMOS y EAPAM (Maipú) y las zonas rurales por Comités de Agua Potable Rural (CAPR). Esta solución fue una de las estrategias concebidas para actuar en la interfaz entre especulación inmobiliaria y la provisión de servicios. Aunque para las empresas privadas los costos de conexión de terrenos lejanos eran muy elevados podían sostenerlo por traspasar los costos a los compradores de las viviendas de clase alta: "estas empresas no quebraron porque se aprovecharon de las subvenciones presupuestarias del agua otorgadas por los urbanizadores, gracias a los ingresos procedentes de la venta de terrenos y edificios" (Pflieger, 2008: 142.). Estos antecedentes indican que cuando la rentabilidad de proyectos de urbanización es lo suficientemente grande, es rentable para el desarrollador organizar la provisión de servicios como electricidad y agua por su propia cuenta.

A modo de ejemplo podemos mencionar la empresa Inmobiliaria Manquehue que construyó Santa Maria de Manquehue, el primer gran barrio cerrado en lo que hoy es el barrio alto consolidado, al cual con los años le siguieron varios otros. Fue también esta inmobiliaria la que fundó Aguas Manquehue (y que era su dueño hasta la compra por Aguas en 2000) para asegurar el abastecimiento de agua. En Chacabuco se replicó este modelo, en parte por los mismos actores, eso sí, a una nueva escala mucho mayor. Hoy día Inmobiliaria Manquehue es líder en el segmento de casas para los sectores medios y altos, siendo su activo más importante Piedra Roja en la comuna de Colina, Provincia de Chacabuco, proyecto emblemático del nuevo urbanismo en Chile. 
Junto con el establecimiento del Código de Aguas en 1981, las reformas más importantes en los sectores del agua y saneamiento han sido las impulsadas a partir del 1989, justo antes del regreso a la democracia. Varios actores importantes influyeron en este nuevo giro, entre ellos grupos económicos con intereses inmobiliarios (Budds, 2013): "A nivel político, el apoyo más ferviente provenía de los beneficiarios potenciales de los efectos de la reforma. Según Shirley et al. (2000: 16), los inversores privados eran el apoyo más importante al proyecto, inversores que se aprovecharían de nuevos contratos como resultado del incremento de la capacidad de inversión, de fuertes presiones para la privatización de la empresa EMOS, y de los posibles desarrollos del sector inmobiliario" (Pflieger, 2008: 142; cursiva de los autores). De esta forma se aprobó la Ley General de Servicios Sanitarios que permite la participación de empresas privadas en las empresas estatales y en 1990 se crea la Superintendencia de Servicios Sanitarios (SISS) que "dispone de poderes de reglamentación equivalentes a los otros reguladores - definición de tarifas, control de los estándares técnicos, atribución de concesiones, control de calidad de los afluentes, etc." (Pflieger, 2008: 144). Así, se inicia un proceso de profunda transformación de EMOS que mejora su capacidad de inversión y culmina en 1999 con la venta del $51 \%$ de sus activos al consorcio hispano francés "Aguas" por el importe récord de US\$ 960 millones (posteriormente cambia su nombre a Aguas Andinas). Al año 2000 Aguas Andinas compra la mayoría de los activos de las empresas privadas del barrio alto, Aguas Manquehue y Aguas Cordillera (que anteriormente se llamaba Agua Potable Lo Castillo).

En resumen, se puede constatar que en Chile hubo un proyecto neoliberal de clase donde sus protagonistas ejercían presiones para la privatización y liberalización de los sectores del agua y del suelo. A su vez, a partir de estas reformas se consolidó un sector inmobiliario con fuerte presencia de los grandes grupos económicos-financieros que ya tenían experiencia en relacionar la urbanización con la provisión de servicios sanitarios. Como es de demostrar, a partir del inicio de los años noventa estos grupos buscaron abrir nuevos mercados para la especulación con el precio del suelo, la producción inmobiliaria y la circulación del capital, es decir, buscaron un nuevo anclaje espacial en la provincia de Chacabuco (Lukas, 2014).

\section{La producción y neoliberalización de la periferia urbana de Santiago: el caso de Chacabuco}

En lo restante de este trabajo nos dedicaremos a detallar los procesos de peri-urbanización neoliberal como un proceso que implica primero la comodificación y posteriormente la financiarización del suelo y del agua. Como se mencionó en la introducción, Chacabuco y en especial la zona de Chicureo es un caso extremo en la producción de desigualdades socioterritoriales y ambientales en varios niveles Lukas 2017: 1) es inédita la escala del territorio que experimenta transformaciones socioterritoriales ligadas a la fragmentación y el metabolismo de recursos; 2) la escala de los megaproyectos urbanos no tiene precedentes en Santiago; 3) la forma en que el Estado se hizo parte de una maniobra de especulación estructural ha sido singular.

Para demostrar cómo la manipulación y el control sobre las relaciones socioambientales en Chacabuco se convirtieron en el principal interés de importantes grupos económicos-financieros a nivel nacional y transnacional y cómo en este contexto se relacionan los circuitos del capital con los circuitos de los recursos naturales en la Provincia de Chacabuco, a continuación, analizamos 
la coevolución de la comodificación, concentración, y financiarización del suelo y del agua y sus efectos territoriales. Desde 1979 (el año de la promulgación de la PNDU y el trabajo en la reforma del Código de Aguas) hasta el presente, distinguimos cinco etapas, donde el interés inmobiliario y financiero en la compra de terrenos coincide con la activación del mercado del agua tanto en transacciones de compra y venta, como en las concesiones otorgadas por parte de la Dirección General de Aguas (DGA) y la privatización de las empresas sanitarias que proveen agua potable a la región. Esta revisión histórica refleja que la activación del mercado de agua coincide con la aplicación de los instrumentos de planificación territorial durante las últimas tres décadas, brindando evidencia sobre la vinculación entre los mercados del suelo, del agua, y el inmobiliario.

Desde la ecología política urbana es importante analizar de qué forma los procesos y relaciones socioambientales específicas y aparentemente locales tienen un carácter multiescalar. En este sentido es relevante reconocer como lo que ocurre en la provincia de Chacabuco está estrechamente relacionado con estrategias territoriales de inversión de grandes grupos económicos-financieros nacionales y transnacionales, siendo estas estrategias a su vez causa y efecto de un proceso de financiarización del desarrollo urbano y del sector sanitario a nivel nacional e internacional (Loftus y March, 2015). Los actores más activos, especuladores estructurales en términos de Logan y Molotch (1987), han sido justamente aquellos grupos que se formaron mediante la apropiación de las ex empresas estatales en el contexto de las políticas de privatización bajo la dictadura militar y que emprendieron en el desarrollo inmobiliario a gran escala. En varios casos la incursión en la especulación estructural se dio después de haber vendido partes importantes de sus nuevos activos a empresas transnacionales (Moenckeberg, 2001). He aquí antecedentes empíricos de la búsqueda de un anclaje espacial para solucionar problemas de sobreacumulación y liquidez de capital en el sentido de Harvey (2001 y 2011).

\section{El surgimiento de los mercados de suelo y agua (1979-1989)}

Durante las décadas de los 70 y 80 , la provincia de Chacabuco era una zona eminentemente rural con la agricultura como la principal fuente de los ingresos de sus habitantes (Nicolas-Artero, 2015). Coexistían varios núcleos urbanos - como Lampa, Colina y Til Til - con una gran variedad de villorrios agrícolas; pero no existían proyectos inmobiliarios comerciales. El crecimiento poblacional que vivieron las comunas era principalmente resultado de la localización de grandes complejos de vivienda social en la cercanía de los centros urbanos existentes. Además, al inicio de los años 80 se instaló en el centro de Colina uno de los centros penitenciarios más importantes del país. La propiedad de la tierra en los centros urbanos en aquella época era fragmentada mientras que en los espacios rurales - que dominaban ampliamente en términos de superficie - existían pequeños agricultores y grandes terratenientes de forma simultánea, producto de la reforma agraria (Armijo, 2000). Especialmente los cerros y sectores de piedemonte correspondían a grandes paños de terreno - muchos sobrepasaban las 1.000 hectáreas - en manos de un propietario (MIMVU, 1997: 14).

Respecto a los recursos hídricos cabe mencionar que el mercado de agua en Chacabuco, como en el resto del país, se hizo efectivo después de la aprobación del Código de Agua en 1981 con la concesión de derechos perpetuos por la Dirección de Aguas (DGA) a privados e instituciones que los solicitaban, sin importantes restricciones sobre el volumen y su uso final. Casi la totalidad de las concesiones otorgadas en Colina y Lampa en esta época se destinaron a privados 
para uso doméstico o sociedades agrícolas para riego. Las empresas sanitarias que solicitaron y recibieron derechos para los centros urbanos de la zona eran empresas públicas: EMOS, Servicomunal y Servilampa (DGA, 2015). Demostrando la todavía minúscula relación del emergente mercado del agua con el mercado inmobiliario, en esta época solamente una empresa del rubro inmobiliario recibe derechos de agua, la Sociedad Agrícola e Inmobiliaria Nogales Ltda., en Colina.

\section{La activación inmobiliaria de Chacabuco y la usurpación del suelo y del agua (1990-1996)}

Iniciando la década de los 90 en las comunas de Lampa y especialmente Colina se instalaron las primeras parcelas de agrado, pequeñas subdivisiones de terreno para casas unifamiliares en predios amplios de media hectárea cada uno, permitidas en zonas rurales. Primero las parcelas de agrado fueron 'autogestionadas' por familias acomodadas, pero luego fueron desarrolladas por empresas inmobiliarias. Lo que buscaban las familias que se mudaron a Lampa y Colina en aquella época era una vivienda en un medio ambiente favorable fuera de la ciudad; una buena relación entre precio y producto en comparación con los sectores tradicionales de las clases medias y altas y un posible negocio futuro, es decir, la posibilidad de vender el terreno a un precio mucho más alto del inicial, una vez que la ciudad alcanzará estos sectores (Poduje y Yañez, 2000). Cómo varios trabajos han mostrado (Armijo, 2000; Poduje y Yañez, 2000; Naranjo 2007), la dinámica que se vio en Lampa y Colina era parte de un proceso más amplio donde también se instalaron parcelas de agrado en las comunas en el sur de Santiago, como en Calera de Tango y Pirque bajo la Ley de Predios Rústicos No. 3156. Cuando en 1994 se promulga el Plan Regulador Metropolitano de Santiago (PRMS), se congela la urbanización y subdivisión en las comunas de la zona sur de Santiago (y se opta en general por una política de densificación y no expansión urbana a nivel metropolitano), y la subdivisión en Colina y Lampa explota. Solo entre 1994 y 1995 se inscribe una superficie de 32.635 hectáreas como parcelas de agrado (de las cuales 19.316 ha correspondían a Colina, 6.371 ha a Lampa y 6.984 ha a Til Til) (MINVU 1997: 15). Un porcentaje menor de estos terrenos se oferta con proyecto inmobiliario en el mercado lo que indica que se trataba de especular con la posterior valorización de la tierra, "o por la llegada de la ciudad o la construcción de las autopistas" (Poduje y Yañez, 2000).

Lo que ocurrió en esta época en la zona norte de Santiago era una ola de especulación sobre el futuro desarrollo urbano en la zona. El hecho de que el desarrollador inmobiliario de vanguardia, Inmobiliaria Manquehue, compró 3.000 hectáreas en el sector de Chicureo el año 1993 llevó a la activación definitiva del mercado del suelo de la zona, al igual que la presencia de ECSA, siendo uno de los socios Sergio de Castro, ex Ministro de Hacienda de Pinochet y el líder de los Chicago Boys. También tenían presencia directa o indirecta los grupos Penta, Hurtado Vicuña, y Fernández León, los nuevos grupos económicos-financieros, algunos conocidos en el sector inmobiliario y otros recién entrando, todos con estrechos lazos al mundo político (Moenckeberg, 2001; Lukas, 2014). De esta forma, en Colina y Lampa se produjo una enorme concentración de poder financiero y político, apostando que por medio de este último sería posible cambiar las reglas del juego, es decir, lograr que el sector público declarara el área de Chacabuco como zona de expansión urbana. En el sentido de Logan y Molotch (1987), estas empresas actuaron como especuladores estructurales, es decir, especularon sobre la futura estructura metropolitana: "estos empresarios especulan sobre su habilidad de cambiar las relaciones de un lugar dado con otro - significa que intentan determinar los patrones a través de los cuales otros van a buscar valores de uso de lugares...intentan cambiar las condiciones del mercado. Su estrategia es crear rentas diferenciales 
a través de influir la arena de toma decisiones que determina ventajas localizacionales" (Logan y Molotch, 1987: 30).

Como se mencionó anteriormente, la transformación de suelos rurales en megaproyectos urbanos al estilo del nuevo urbanismo no era posible ni técnica ni legalmente sin asegurar la provisión de agua. Así, dada la necesidad de asegurar el suministro de agua para sus proyectos, a mediados de la década de los 1990 aparecen las primeras empresas inmobiliarias en el mercado de agua. Es importante recordar que según el Código de Aguas del 1981 el agua fue separada de la tierra, facilitando la compra de agua de cualquier terreno. En comparación con la década anterior, durante los 1990 las solicitudes de concesiones de derechos de agua se duplicaron, y entre los actores que adquirieron derechos figuran no solo numerosas empresas inmobiliarias sino también constructoras, sanitarias y sociedades anónimas. He aquí una muestra de que no solamente se activó un mercado inmobiliario con sus inherentes procesos de especulación, sino que la especulación también se extendió al mercado de los derechos de agua. También es durante este periodo que se crean cinco de los once CAPR efectivos en las comunas de Colina y Lampa. ${ }^{6}$

\section{El Plan Chacabuco y la negociación de los megaproyectos (1997 - 2001)}

Después de fuertes presiones políticas por parte del sector inmobiliario y los grupos económicos asociados, en 1996 el MINVU presentó una primera propuesta de cómo integrar la provincia de Chacabuco al PRMS, el llamado Plan Chacabuco (Lukas, 2014). De inmediato se levantaron fuertes críticas a la propuesta que básicamente consistía en declarar vastas zonas de la provincia como territorio urbanizable. Algunas de las críticas más importantes se referían a la consecuente pérdida de terrenos agrícolas, a los problemas de escasez de agua ya existentes en la cuenca y a la discrecionalidad con las que se iban a valorizar terrenos de algunos empresarios políticamente influyentes. En contra de las críticas y después de intensas disputas, el año 1997 se aprueba el Plan Chacabuco. Aparte de la incorporación de la provincia al PRMS, la principal medida fue la designación de suelo urbanizable bajo un nuevo tipo de zonificación de uso de suelo: las Zonas Urbanas de Desarrollo Condicionado (ZODUC). A través de esta medida el área urbanizable del Gran Santiago aumentó 7.600 hectáreas de las cuales solo 5.490 hectáreas correspondieron a las 8 empresas con megaproyectos en carpeta (Poduje y Yañez, 2000), hecho por el cual el Estado chileno mostró una clara "selectividad espacial" (Brenner, 2003) y se cumplió el primer paso en la maniobra de la especulación estructural.

Para legitimar su selectividad espacial en favor de los especuladores estructurales, junto con las ZODUC, el gobierno inventó la así llamada "planificación por condiciones". Esta implica, muy en contra de la política de frenar la expansión urbana del PRMS 1994, que el Estado ahora permite la expansión urbana en suelos rurales, pero define condiciones de urbanización que los desarrolladores tienen que cumplir. En el caso de las ZODUC las condiciones se refieren a cierto tamaño mínimo de los proyectos (300 hectáreas), una cierta mezcla de actividades (el $5 \%$ de la superficie urbanizable debe estar destinado a usos de servicios y equipamientos) y segmentos de población (el 5\% debe estar destinado a zonas con densidades que debían inducir la construcción de

Los restantes CAPR se crean hasta el 2001, último año en que se creó un Comité de Agua Potable Rural, y al mismo tiempo el inicio de la etapa de compra de las sanitarias por empresas multinacionales, indicando una transición en la configuración regional de gestión de agua. 
viviendas sociales) en los proyectos y el financiamiento de la infraestructura (agua potable, aguas lluvias, transporte, etc.) necesaria. Además, a través de la definición de una densidad promedio de 85 hab/ha se aumentó la constructibilidad de las parcelas por un factor de ocho (Poduje y Yañez, 2000). Aunque con este plan el Estado chileno contradijo su principal política acerca del desarrollo de su capital, es decir, abogar por el crecimiento por densificación, el MINVU justificó el plan en nombre de la sustentabilidad y una mejor coordinación de inversiones públicas y privadas (MINVU, 1997). En la práctica, el Estado dio luz verde a ganancias exorbitantes para grupos económicos vinculados a la derecha política, los poderes fácticos, y a un proceso de profunda fragmentación territorial y socioambiental en la periferia de Santiago. Con respecto a la situación del agua, los megaproyectos se comprometieron a construir sistemas de agua potable, alcantarillado y sistemas de aguas lluvias. En algunos casos las inmobiliarias fundaron empresas propias (Novaguas en Valle Grande, Brisaguas en Brisas de Chicureo) como lo habían hecho antes en el barrio alto, mientras que en otros se hacía cargo Aguas Manquehue (en Piedra Roja, La Reserva y Valle Norte). Los megaproyectos inmobiliarios lograron importantes subsidios respecto al agua, especialmente Piedra Roja (y el condominio Polo de Manquehue), para el cual se fijó una tarifa que era $160 \%$ debajo de la tarifa que regía en el resto de la zona de concesión de Aguas Andinas en la Región Metropolitana. Esta tarifa se había fijado en el 2000 y se mantuvo hasta el año 2010, momento en que la SISS corrigió esta situación, constituyendo durante 10 años un subsidio importante para los habitantes de la zona (Esturillo, 2010).

Con respecto al mercado del agua cabe mencionar que desde el año 1996, cuando ya existían claras señales sobre la futura modificación del PRMS que permitiría la urbanización en Chacabuco, y hasta el 2002, cuando empieza la construcción de grandes proyectos inmobiliarios en la zona, ocurrió una intensificación de transacciones en el mercado de agua sin precedentes en Lampa y Colina, teniendo el año 1998 como zenit histórico. Lo anterior podría contribuir a explicar que el precio del agua se triplicara durante este periodo, con el valor promedio anual de un caudal equivalente a $1 \mathrm{lt} / \mathrm{s}$ subiendo desde los 750.000 pesos en 1997 a los 2.160 .000 pesos el 2002. Al mismo tiempo, se observó cómo las inmobiliarias tuvieron una participación variable pero importante en las concesiones de derechos de agua en la zona, llegando a representar el $59 \%$ de los derechos concedidos en un año.

La tendencia descrita en el mercado de agua está marcada por el temprano y progresivo interés de las empresas inmobiliarias en la adquisición de derechos en la zona, junto con las primeras construcciones masivas, principalmente en la comuna de Colina. Dicho interés se atribuye al hecho que en esta etapa las inmobiliarias organizaban el suministro de agua de sus correspondientes proyectos inmobiliarios de forma particular. Como consecuencia, entre los años 1999 y 2002, las concesiones de derechos de aguas a empresas inmobiliarias presentes en la zona fueron equivalentes al $30 \%$ del total en volumen de agua.

\section{La implementación de los megaproyectos y la transnacionalización del agua (2002 - 2008)}

Después de la firma del Acuerdo Marco el 2001, que fijaba las mitigaciones y condiciones entre las ocho inmobiliarias y distintos ministerios del Estado, hecho que fue celebrado como un gran hito en la cooperación pública-privada en el desarrollo urbano en Chile, en el año 2002 los primeros megaproyectos - Piedra Roja, La Reserva y Valle Grande - iniciaron su fase de construcción 
(Figura 2). Para la comercialización y el reconocimiento de un proyecto inmobiliario como lugar con identidad propia, se comienza el desarrollo con la construcción de macroinfraestructura por un lado y por el otro de amenidades como lagunas artificiales, canchas de golf y amplios espacios verdes a lo largo de las calles principales. La mayoría de los proyectos quiere proyectar en su diseño y nombre un estilo de vida ligado a la naturaleza, la abundancia de agua y áreas verdes y al ocio. Así, dentro de un contexto bioclimático semiárido y con problemas de escasez de agua, varios de los proyectos se comercializan como eco-ciudades o ciudades verdes. ${ }^{7}$ Los primeros años de vida de los megaproyectos son especialmente intensivos tanto en la inversión de recursos financieros como en el uso de recursos hídricos en relación con los pocos habitantes que existían en esta fase. Cabe recordar que en general los megaproyectos tienen un horizonte de desarrollo de entre $20 \mathrm{y}$ 30 años, donde la lógica consiste en aumentar paulatinamente el valor del suelo. ${ }^{8}$

En el mismo periodo, y junto a los megaproyectos, las parcelas de agrado siguen expandiéndose. Estos asentamientos no tienen infraestructura sanitaria y se reporta la construcción y explotación de muchos pozos ilegales, es decir, no declarados y sin derechos de agua asignados. Las napas subterráneas explotadas por los pozos legales e ilegales también son usadas como fuente de abastecimiento de las lagunas artificiales creadas en la zona como la de Piedra Roja. En este panorama dominado por nuevos e intensivos usos hídricos y el considerable crecimiento poblacional, se produjo una creciente competencia por el agua que se manifestó en el mercado de aguas de la zona tanto respecto al aumento en el número de transacciones como en el aumento del precio de los derechos transados durante este periodo. Otro factor que agrava esta situación, y es evidencia de la creciente competitividad y dificultad de acceso al agua, es la fundación de seis Comités de Agua Potable Rural durante esta etapa.

Entre 2003 y 2009 se consolida el escenario actual de gestión y acceso al agua en la zona, donde se sigue manifestando un fuerte interés por la adquisición de derechos de agua. Esto es visible tanto en la intensa movilidad en el mercado de agua como en las concesiones de derechos de agua por parte de la DGA. Es importante resaltar que en este periodo el precio promedio del derecho a explotación de un caudal equivalente a $1 \mathrm{lt} / \mathrm{s}$, llegó a los 2.800 .000 pesos. Paralelamente, las solicitudes de concesión de derechos de agua a la DGA indica la misma tendencia, con el número de solicitudes superando el promedio histórico por $40 \%$ y $200 \%$ en Colina y Lampa respectivamente. Los intereses de las empresas inmobiliarias por el control hídrico de la zona se develan en el hecho de que en el año 2000 las solicitudes de concesión de derechos de agua por parte de las inmobiliarias representaban el $39 \%$ del total de las solicitudes en Lampa y $59 \%$ en Colina.

Este periodo también fue marcado por una importante evolución en el sector de gestión de agua urbana, ya que a partir del año 2003 en la Provincia de Chacabuco se observa la entrada de empresas transnacionales del sector sanitario. Esto coincide tanto con el hecho de que ya existía una demanda real por parte de los megaproyectos y la expansión de la política de privatización de las empresas sanitarias municipales en todo el país. Esto último se hace efectivo en Chacabuco en año 2004, cuando la empresa multinacional SEMBCORP compra la empresa Servicios de Agua

"Chicureo se transforma en una ciudad verde", http://www.edicionesespeciales.elmercurio.com/destacadas/detalle/index.asp?idnoticia $=20140725165228$

3 "La estrategia principal de la empresa es la focalización en macroproyectos inmobiliarios de largo plazo, que capturen sus externalidades positivas para beneficio del negocio. El desarrollo de proyectos a gran escala permite transferir entre etapas los beneficios de las inversiones realizadas desde un comienzo, generando con ello plusvalias en los saldos de terrenos por desarrollar" (Memoria Inmobiliaria Manquehue 2009). 
Potable Biwater S.A. (SAPBSA) constituida en 1994, y la transforma en Aguas Santiago S.A. Esta transacción marcó el inicio de la actividad de la empresa multinacional en la zona. En el año 2008 Aguas Santiago S.A. compró las empresas Servicomunal, Aguas Chacabuco y Aguas Lampa. Por otro lado, el año 2002 se finaliza la compra de Aguas Manquehue por parte de Aguas Andinas, la mayor empresa sanitaria a nivel nacional, controlada por el grupo AGBAR-Suez. Este mismo año Aguas Andinas también adquiere a Aguas Cordillera, proceso relacionado con procesos macroestructurales en el contexto de la financiarización y transnacionalización del mercado de agua a nivel global (March y Purcell, 2014). En resumen, en esta fase la provisión de agua en gran parte de Lampa y Colina ha sido traspasada a empresas transnacionales con el resultado de que en 2012 más del $80 \%$ de los clientes residenciales en las comunas de Lampa y Colina eran atendidos por dos empresas: Agbar-Suez (20\%) y SEMBCORP (60\%). Por el otro lado existen 4 CAPR en Lampa (abasteciendo aprox. 37.000 personas) y 13 en Colina (abasteciendo aprox. 23.000 personas).

\section{Despunte de ventas, financiarización, y el problema de la escasez de agua (desde 2009)}

Un hito en la consolidación de Colina y Lampa - y especialmente el sector de Chicureo - como principal frente de desarrollo inmobiliario para las clases media-altas fue la inauguración de la Autopista Nororiente ${ }^{9}$ en 2009, ya que disminuyó de forma considerable los tiempos de viaje entre Sanhattan (centro de negocios de Santiago), el barrio alto consolidado y Chicureo (Lukas y López, 2018) (Figura 2). A partir de 2009 han despuntado las ventas y hoy día Chicureo se ha configurado como una nueva centralidad metropolitana, un lugar con cierta identidad (producida por el marketing territorial de los desarrolladores inmobiliarios), una amplia oferta de servicios y donde al año 2014 vivían alrededor de 25.000 personas. Hoy Colina es la comuna con la mayor concentración de inversiones inmobiliarias previstas en todo el país ya que para el quinquenio 2017-2021 "se catastraron nueve iniciativas, por US\$1.591 millones [...] destacando los proyectos Piedra Roja (US\$ 614 millones a ejecutar en el quinquenio), Santa Elena (US\$ 425 millones) y La Reserva (US\$ 128 millones)" (El Mercurio, 3 de noviembre 2017).

Como ocurre en general en el mercado del suelo del Gran Santiago (Cattaneo, 2011; Gasic, 2018), en Lampa y Colina se observa una creciente entrada en la compra y venta de terrenos, aparte de los desarrolladores inmobiliarios existentes, de entidades financieras, como bancos, sociedades de inversiones, fondos inmobiliarios y fondos de pensiones (Lukas, 2014). Empresas como Inmobiliaria Manquehue o el holding Consorcio (asociado a los grupos económicos-financieros Hurtado Vicuña, Fernandéz León y Matte) controlan grandes extensiones de terrenos donde en parte desarrollan sus megaproyectos, en parte venden a inmobiliarias tradicionales (como Aconcagua o Siena), y en parte esperan a futuras oportunidades de negocio. El esquema que se ha establecido es el del Mayorista del Suelo (Yañez y Poduje, 2000), donde un desarrollador inmobiliario o un consorcio planifica, implementa y administra una ZODUC en su totalidad para vender macrolotes desarrollables a inmobiliarias tradicionales y donde su negocio consiste principalmente en aumentar el precio del suelo para posteriormente capturar la brecha de renta. Para ilustrar el rotundo éxito comercial de esta estrategia sirve saber que el precio del metro cuadrado

Cabe mencionar que la construcción de la autopista fue propuesta al sistema de concesiones de obras públicas por parte de ECSA, desarrollador del megaproyecto Chamisero en Chicureo, fue construida con importantes subsidios estatales por la multinacional española SACYR, y después vendida al consorcio italiano Benetton, otros antecedentes sobre la transnacionalización de la nueva periferia urbana (Lukas, 2014). 
Figura 2: Configuración espacial de los diferentes usos de suelo y tipos de urbanización

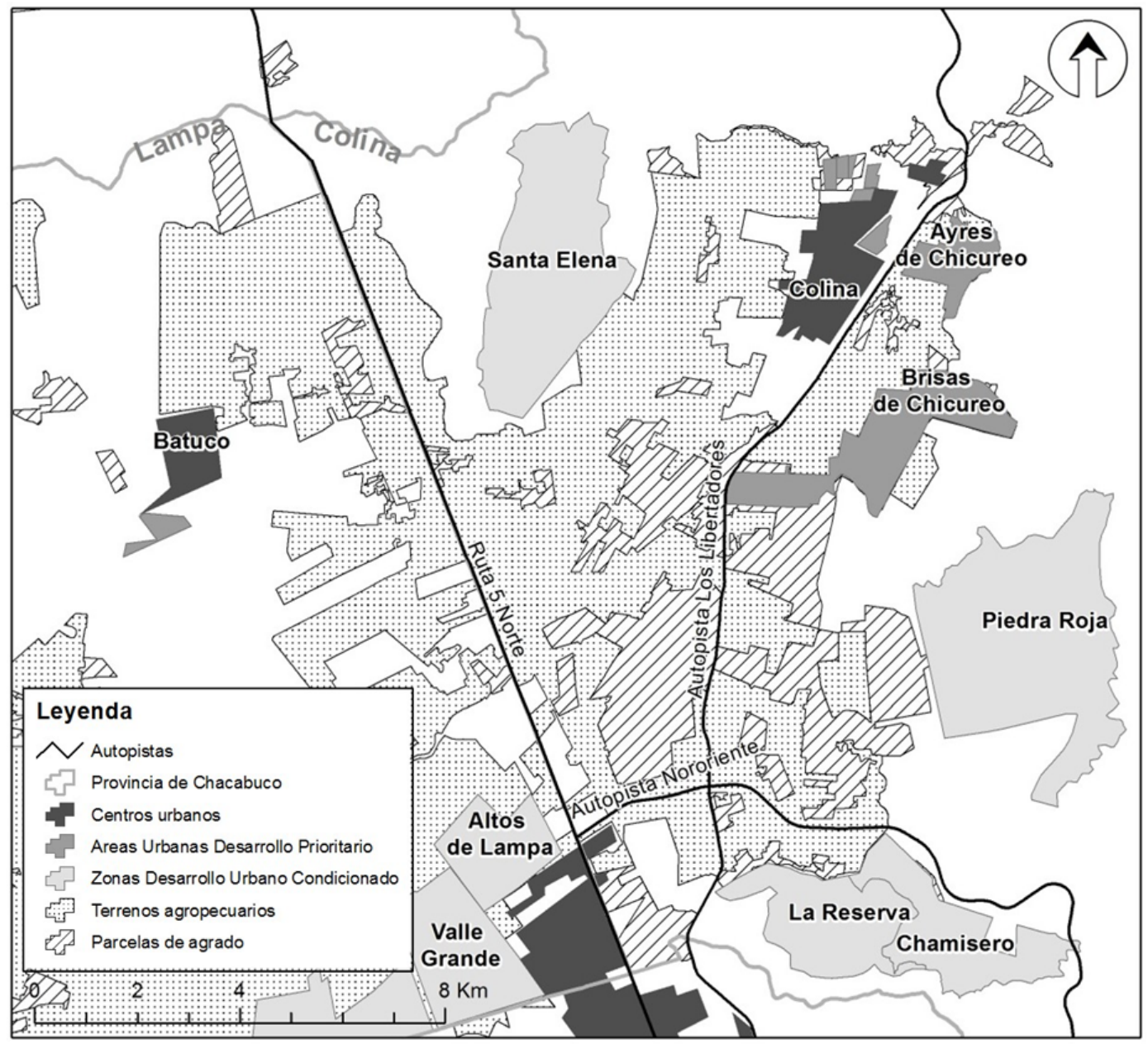

de suelo en Chicureo antes del PRMS 1997 valía alrededor de 1,9 US\$, con la introducción de la figura de los ZODUC subió a 8,2US\$ y hoy oscila, entre 43 y 92 US $\$$ en Piedra Roja, sin construcción (precio que pagan las inmobiliarias para adquirir un macrolote), y entre 2.732 y 4.000 US $\$$ por metro cuadrado construido (precio que paga el comprador final de la vivienda). ${ }^{10}$

Tal como en el caso del recurso del suelo, el agua ha experimentado un proceso secuenciado de comodificación, concentración (de derechos de propiedad) y financiarización. Hoy día los derechos de agua están en manos de desarrolladores inmobiliarios, de sanitarias transnacionales y sociedades de inversión, afectando de forma definitiva el ciclo hídrosocial (Budds, 2012). Emblemático es el caso de los megaproyectos que cuentan con modernas infraestructuras y redes de abastecimiento operados por sanitarias transnacionales. De los diez sectores que mostraron

En las cifras se trata de estimaciones para indicar el rango grueso de valores. Se basa en distintas fuentes, estudios académicos (Yañez y Poduje, 2000), notas de prensa, información comercial en la página de Piedra Roja y avisos de venta de casas online. 
el consumo de agua per cápita más alto del país en 2011, tres correspondian a megaproyectos en Chicureo, a saber, La Reserva, Piedra Roja y Valle Grande. La Reserva tenía el consumo residencial de agua más alto del país, alcanzando los 1.120 litros de agua por persona diariamente, mientras el promedio de consumo recomendado por la SISS es entre 100 y 200 litros (Rivera, 2011).

La instalación de estos usos intensivos de agua ha agravado la situación de escasez en Colina, Lampa y Til Til. Desde el año 2008 en variadas ocasiones las tres comunas han sido declaradas Zonas de Escasez Hídrica por parte del Ministerio de Obras Públicas. En 2013, en paralelo a la declaración de Zona de Escasez, los pobladores del CAPR de Santa Filomena, en Chicureo, se organizaron para protestar públicamente por la falta de agua. Mientras las protestas indicaron a los megaproyectos directamente colindantes como responsables de la escasez, la empresa Aguas Chacabuco de forma bastante lapidaria culpó a la "constante apertura de grifos". Otros sospechosos como responsables de la escasez de agua son el cambio climático y la mega sequía. Si bien estos fenómenos efectivamente afectan a toda la cuenca norte de Santiago, no todos los habitantes sufren las consecuencias de la misma forma sino que recaen especialmente en las CAPR. Hay varios de ellos que muestran problemas de abastecimiento, bajas considerables en los niveles de los pozos e incluso agotamiento de sus fuentes (Entrevistas a directivas CAPR). En estos casos, y dada la ausencia de intervención estatal, los CAPR tienen como única opción abastecerse de agua potable por las empresas sanitarias de la zona mediante camiones aljibe. En estos casos el precio del agua llega a los 10.000 pesos por $\mathrm{m}^{3}$ (Entrevista a Directora de una CAPR), lo que es hasta alrededor de 30 veces más costoso que el suministro del CAPR.

Lo que cada vez se hace más evidente en Chacabuco es una eminente sobre-explotación de las napas freáticas y la disminución de la recarga del acuífero (Nicolas-Artero, 2015), que en un contexto de una decreciente disponibilidad de agua por los efectos del cambio climático (Adapt Chile, 2015) Ileva a una competencia cada vez más aguda. Aunque hasta el momento los clientes de los megaproyectos no parecieran sentir la escasez de agua, las sanitarias transnacionales ya se están preparando para escenarios futuros e iniciaron la construcción de una nueva planta de producción de agua potable en el sector de Chamisero por parte de Aguas Andinas (Mardones, 2017). El hecho de que la planta utilizará agua del Rio Maipo, a 60 kilómetros de distancia de Chicureo y perteneciente a otra cuenca, que por lo demás se encuentra en disputa hace varios años por la instalación de una planta hidroeléctrica que afectará el caudal del rio, reafirma el re-escalamiento del impacto de la especulación estructural y financiarización de los recursos naturales en Chacabuco sobre los flujos metabólicos a nivel metropolitano (Lukas y Fragkou, 2014). Que la nueva planta este diseñada para abastecer exclusivamente a los barrios Piedra Roja y Chamisero, en Colina, y parte de la comuna de Lampa, "manteniendo así un alto estándar de servicio para nuestros clientes" (en las palabras del gerente corporativo de Servicio al Cliente de Aguas Andinas), bypaseando los territorios hídricos comunales, confirma la constitución definitiva de una geografía de archipiélagos, el confinamiento de los comunes hídricos, y la focalización hacia las elites.

\section{Conclusiones}

La provincia de Chacabuco puede ser entendida como una nueva periferia neoliberal debido a que ha sido construida por una coalición entre el Estado y los beneficiarios del modelo neoliberal en Chile. Han sido grandes grupos económicos-financieros y desarrolladores inmobiliarios espe- 
cializados que lograron concretizar sus estrategias de especulación estructural en Chacabuco e inscribir sus intereses de valorización territorial en los sistemas públicos de planificación urbana-regional, es decir, lograron definir una selectividad estatal espacial específica en su beneficio. En este sentido, el paisaje de archipiélagos de nuestro caso de estudio es un reflejo de las relaciones de poder vigentes en Chile en los años posteriores a la redemocratización.

Parte integral de esta territorialización del control corporativo ha sido la comodificación, concentración (de derechos de propiedad) y financiarización del suelo y del agua. Los poderes fácticos se han apropiado - vía procesos legislativos, administrativos y transacciones de mercado - de las tierras y del agua en Chacabuco en una escala sin precedentes y están en proceso de despojar a los antiguos dueños del acceso a estos recursos naturales. En este sentido, tanto el suelo y el agua han sido subsumidos a la lógica del capital financiero, sus actores, instituciones y estrategias de inversión y acumulación. Hoy día, el agua fluye en la dirección de los territorios corporativos, dejando los territorios hídricos comunales paulatinamente sin agua, tal como Budds (2012) caracteriza el ciclo hidrosocial. Como mostramos, estos hechos no son resultados de procesos abstractos y de macroescala, como se lo entendió en la primera fase de la discusión sobre la relación entre globalización y fragmentación, sino son procesos deliberados con actores e instituciones específicas.

El Estado juega un rol fundamental en este proceso a través de su selectividad estratégica y espacial, reafirmando lo planteado por Budds (2013) en el sentido que la comodificación del agua, más que un mero resultado del proyecto neoliberal fue un requisito para su realización y éxito. Nuestros resultados avanzan en este sentido demostrando que el Código de Aguas no solamente aseguró el abastecimiento hídrico de los sectores económicos de interés de la dictadura militar, como el minero e hidroeléctrico (Budds, 2013), sino también benefició al sector inmobiliario y en particular los grupos económicos-financieros que lo soportan, definiendo así las nuevas formas de producir periferias urbanas. En este sentido, la provincia de Chacabuco y especialmente sus megaproyectos pueden ser interpretados como parte de un anclaje espacial del proyecto neoliberal en Chile (Lukas, 2014).

El resultado de los procesos de la territorialización del poder corporativo en la Provincia de Chacabuco, es una doble desigualdad. Por un lado, en la nueva periferia urbana los actores tienen acceso a redes de agua de distinto costo, continuidad temporal, seguridad y tecnología, a diferencia a lo que pasa en el área urbana consolidada de Santiago, donde hay acceso universal y homogéneo a la red de agua potable. Por el otro lado, y en su calidad de consumidores de agua, la población de Chacabuco se puede distinguir en los nuevos habitantes, que consumen cantidades exuberantes e insustentables a menores precios, y los antiguos, que sufren de una disminución de la disponibilidad para su consumo. Este fenómeno en Santiago tiene una evidente dimensión de clase, ya que es la clase rentista-financiera en forma de los grupos económicos-financieros que captura la renta del suelo y la clase media-alta que se instala en los territorios corporativos usurpando los recursos naturales como el suelo y el agua. De forma similar, los efectos de la sequía que está afectando a la zona durante los últimos años impacta de manera diferenciada a la población, ya que los habitantes de los mega proyectos inmobiliarios no tienen problemas de suministro de agua debido a que todos los recursos estatales y privados se movilizan para ello, mientras que los problemas de escasez afectan gravemente a los territorios hídricos comunales 
rezagados. En este contexto, es de esperar que los conflictos ya existentes sobre el agua se profundicen en la medida que los efectos del cambio climático se hagan más evidentes en el futuro.

Por último, podemos constatar que la ecología política urbana efectivamente puede hacer aportes importantes a los trabajos sobre la ciudad latinoamericana en general y al estudio y la comprensión de sus periferias urbanas en particular. Lo anterior, a partir principalmente de desfetichizar y develar el complejo entramado entre actores, instituciones y flujos materiales y metabólicos en la producción de nuevas socio-naturalezas. Pero también este tipo de trabajo complementa el conocimiento existente sobre las relaciones públicas-privadas en la producción, planificación y gentrificación de la ciudad que hasta el momento ha girado casi exclusivamente en torno a espacios urbanos centrales y peri-centrales, dejando fuera de la agenda las formas en que el capitalismo financiero usa, instrumentaliza y produce nuevos procesos de desarrollo geográfico desigual más allá de los tradicionales límites de la ciudad.

\section{Bibliografía}

ABRAMO, P. La ciudad com-fusa: mercado y producción de la estructura urbana en las grandes metrópolis latinoamericanas. EURE, 2012, Vol. 38 N¹14, p. 35-69.

ADAPT CHILE. Plan Local de Cambio Climático. Comuna de Colina 2015. Santiago de Chile, 2015.

AHLERS, R.; MERME, V. Financialization, water governance, and uneven development. WIREs: Water, 2016, Vol. $3 \mathrm{~N}^{\circ} 6$, p. 766-774.

ANGELO, H.; WACHSMUTH, D. Urbanizing urban political ecology: A critique of methodological cityism. International Journal of Urban and Regional Research, 2015, Vol. 39 №1, p. 16-27.

ARBOLEDA, M. Financialization, totality and planetary urbanization in the Chilean Andes. Geoforum, 2015a, Vol. 57 N¹, p. 4-16.

ARBOLEDA, M. The biopolitical production of the city: urban political ecology in the age of inmaterial labour. Environment and Planning D: Society and Space, 2015b, Vol. 33, p. 35-51.

ARBOLEDA, M. In the Nature of the Non-City: Expanded Infrastructural Networks and the Political Ecology of Planetary Urbanisation. Antipode, 2016, Vol. 48 N², p. 233-251.

ARMIJO, G. La faceta rural de la Región Metropolitana: entre la suburbanización campesina y la urbanización de la elite. EURE, 2000, Vol. 26 №78, p. 131-135.

BAKKER, K. Archipelagos and networks: Urbanization and water privatisation in the South. Geographical Journal, 2003, Vol. 169 N4, p. 328-341.

BORSDORF, A.; HIDALGO, R. \& SANCHEZ, R. A new model of urban development in Latin America: the gated communities and fenced cities in the Metropolitan Areas of Santiago de Chile and Valparaíso. Cities, 2007, Vol. 24 N5, p. 365-378. 
BRENNER, N. Glocalization' as a state spatial strategy: urban entrepreneurialism and the new politics of uneven development in western Europe. En: Peck, J. y Yeung, H. (editores): Remaking the Global Economy: Economic-Geographical Perspectives. London: Sage, 2003, p. 197-215.

BUDDS, J. La demanda, evaluación y asignación del agua en el contexto de escasez: un análisis del ciclo hidrosocial del Valle del Río la Ligua, Chile. Revista de Geografía Norte Grande, 2012, Vol. 52 N¹, p. 167-184.

BUDDS, J. Water, power, and the production of neoliberalism in Chile, 1973-2005. Environment and Planning D: Society and Space, 2013, Vol. 31 N²$^{\circ}$, p. $301-318$.

BUDDS, J.; MCGRANAHAN, G. Are the debates on water privatization missing the point? Experiences from Africa, Asia and Latin America. Environment and Urbanization, 2003, Vol. $15 \mathrm{~N}^{\circ} 2$, p. 87-114.

CALDEIRA, T. Peripheral urbanization: Autoconstruction, transversal logics, and politics in cities of the global south. Environment and Planning D: Society and Space, 2017, Vol. 35 N¹, p. 3-20.

CASTÁN BROTO, V.; ALLEN, A. \& RAPOPORT, E. Interdisciplinary perspectives on urban metabolism. Journal of Industrial Ecology, 2012, Vol. 16 N$^{\circ} 6$, p. 851-861.

CASTRO, C. Impacto de la dispersión urbana de la ciudad de Santiago en la calidad del suelo en la periferia norte: Colina y Lampa. Scripta Nova - Revista Electrónica de Geografía y Ciencias Sociales, 2005, Vol. $194 \mathrm{~N}^{\circ} 37$.

CATTANEO, R. Los fondos de inversión inmobiliaria y la producción privada de vivienda en Santiago de Chile: ¿Un nuevo paso hacia la financiarización de la ciudad? EURE, 2011, Vol. 37 №112, p. 5-22.

CICCOLELLA, P. Globalización y dualización en la Región Metropolitana de Buenos Aires. Grandes inversiones y reestructuración socioterritorial en los años noventa. EURE, 1999, Vol. 25 №76, p. 5-27.

CROT, L. 'Scenographic' and 'cosmetic' planning: Globalization and territorial restructuring in Buenos Aires. Journal of Urban Affairs, 2006, Vol. $28 \mathrm{~N}^{\circ} 3$, p. 227-251.

CUENYA, B.; CORRAL, M. Empresarialismo, economía del suelo y grandes proyectos urbanos: el modelo de Puerto Madero en Buenos Aires. EURE, 2011, Vol. 37 №111, p. 25-45.

DE MATTOS, C.; FUENTES, L. \& LINK, F. Tendencias recientes del crecimiento metropolitano en Santiago de Chile: ¿Hacía una nueva geografía urbana? Revista INVI, 2014, Vol. 29 N81, p. 193-209.

DGA. Derechos de aprovechamiento de aguas registrados en DGA - Región Metropolitana. Dirección General de Aguas 2015. Última actualización el 7 de julio 2015. Disponible en: http://www. dga.cl/productosyservicios/derechos_historicos/Paginas/default.aspx 
DOMENE, E. La ecología política urbana: una disciplina emergente para el análisis del cambio socioambiental en entornos ciudadanos. Documents d'Anàlisi Geogràfica, 2006, Vol. 48, p. 167-178.

DURAN, G. Agua y pobreza en Santiago de Chile. Morfología de la inequidad en la distribución del consumo de agua potable. EURE, 2015, Vol. $41 \mathrm{~N}^{\circ} 124$, p. 225-246.

ESTURILLO, J. Tarifas de agua en Chicureo suben 160\%. El Mercurio, 21 de agosto 2010. Disponible en Internet: http://www.economiaynegocios.cl/noticias/noticias.asp?id=76755

FERNÁNDEZ, L; HERRERO, A. \& MARTíN, I. La impronta del urbanismo privado. Ecología de las urbanizaciones cerradas en la Región Metropolitana de Buenos Aires. Scripta Nova - Revista Electrónica de Geografía y Ciencias Sociales, 2010, Vol. 14 №331.

FERNÁNDEZ JILBERTO, A. Neoliberal restructuring. The origin and formation of economic groups

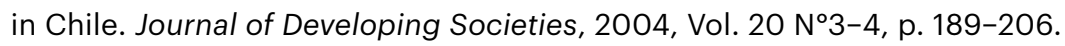

FISCHER, K. Eine Klasse für sich. Besitz, Herrschaft und ungleiche Entwicklung in Chile, 18302010. Baden-Baden: Nomos, 2011.

GASIC, I. Inversiones e intermediaciones financieras en el mercado del suelo urbano. Principales hallazgos a partir del estudio de transacciones de terrenos en Santiago de Chile, 2010-2015. EURE, 2018, Vol. 44 Nº133, p. 29-50.

GRAHAM, S.; MARVIN, S. Splintering urbanism: Networked, Infrastructure, Technological Mobilities and the Urban Condition. New York: Routledge, 2001.

GUIBRUNET, L; SANZANA CALVET, M. \& CASTÁN BROTO, V. Flows, system boundaries and the politics of urban metabolism: Waste management in Mexico City and Santiago de Chile. Geoforum, 2017, Vol. 85, p. 353-367.

HARVEY, D. From Managerialism to Entrepreneurialism: The Transformation in Urban Governance in Late Capitalism. Geografiska Annaler, 1989, Vol. 71 №1, p. 3-17.

HARVEY, D. Globalization and the "Spatial fix". Geographische Revue, 2001, Vol. 3 N², p. 23-30.

HARVEY, D. The Enigma of Capital and the Crisis of Capitalism. London: Profile Books, 2011.

HEINRICHS, D.; LUKAS, M. \& NUISSL, H. Privatisation of the fringes - a Latin American version of post-suburbia? The Case of Santiago de Chile. En: Phelps, N.; Wu, F. (editores) International perspectives on Suburbanization: A postsuburban world? London: Palgrave-MacMillan, 2011, p. 101-121.

HEYNE, N.; KAIKA, M. \& SWYNGEDOUW, E. Urban political ecology. En: Heynen, N., Kaika, M. and Swyngedouw, E. (eds.): In the nature of cities. London, Routledge, 2006. 
HIDALGO, R.; BORSDORF, A.; ZUNINO, H. \& ALVAREZ, L. Tipologías de expansión metropolitana en Santiago de Chile: precariópolis estatal y privatópolis inmobiliaria. Scripta Nova - Revista Electrónica de Geografía y Ciencias Sociales, 2008, Vol. 12 №270.

JANOSCHKA, M. El nuevo modelo de la ciudad latinoamericana: fragmentación y privatización. EURE, 2002, Vol. $27 \mathrm{~N}^{\circ} 85$, p. 11-29.

KEIL, R. Suburban Constellations: Governance, Land and Infrastructure in the 21st Century. Berlin: Jovis Verlag, 2013.

KEIL, R. Extended urbanization, "disjunct fragments" and global suburbanisms. Environment and Planning D: Society and Space, 2018, Vol. 36 №3, p. 494-511.

KNOX, P. Metroburbia, USA. New Brunswick: Rutgers University Press, 2008.

LEFEBVRE, H. Urban Revolution. Minnesota: Minnesota University Press, 2003.

LOFTUS, A.; MARCH, H. Editorial: Financialising Nature? Geoforum, 2015, Vol. 60, p. 172-175.

LOGAN, J.; Molotch, H. Urban Fortunes. The Political Economy of Place. Berkeley: University of California Press, 1987.

LÓPEZ, E. Gentrificación en Chile: aportes conceptuales y evidencias para una discusión necesaria. Revista de Geografía Norte Grande, 2013, Vol. 56, p. 31-52.

LÓPEZ, E. Gentrification in Santiago, Chile: a property-led process of dispossession and exclusion. Urban Geography, 2016, Vol. 37, N8, p. 1109-1131.

LUKAS, M. Neoliberale Stadtentwicklung in Santiago de Chile. Akteurskonstellationen und Machtverhältnisse in der Planung städtebaulicher Megaprojekte. Kiel: Christian Albrechts Universität zu Kiel (Kieler Geographische Schriften Band 125), 2014.

LUKAS, M.; FRAGKOU, M.C. Conflictividad en construcción: desarrollo urbano especulativo y gestión de agua en Santiago de Chile. Revista Ecología Política, 2014, Vol. 47, p. 67-71.

LUKAS, M. Las nuevas periferias urbanas, territorios en disputa. In: Imilan, W et al. (eds.): ¿Hacía dónde va la vivienda en Chile? Nuevos desafíos en el hábitat residencial. Santiago: Adrede Editora: 2017, p.199-214.

LUKAS, M.; LÓPEZ, E. Real estate production, geographies of mobility and spatial contestation: a two-case study in Santiago de Chile. Journal of Transport Geography, 2018, Vol. 67, p. 92-101.

MARDONES, C. Nueva planta de agua potable en Chicureo se abastecerá de caudal del río Maipo. El Mercurio, 24 de junio de 2017, Disponible en Internet: https://www.latercera.com/noticia/nueva-planta-agua-potable-chicureo-se-abastecera-caudal-del-rio-maipo/ 
MCKINNON, I; HURLEY, P.; MYLES, C.; MACCARONI, M. \& FILAN, T. Uneven urban metabolisms: toward an integrative (ex)urban political ecology of sustainability in and around the city. Urban Geography, 2017, p. 1-26.

MINVU. Política Nacional de Desarrollo Urbano. Santiago de Chile, 1981.

MINVU. Memoria Explicativa del Plan Regulador Metropolitano de Santiago. Modificación PRMS-Incorporación de las comunas de Colina, Lampa y Til Til. Santiago de Chile, 1997.

MARCH, H.; PURCELL, T. The muddy waters of financialisation and new accumulation strategies in the global wáter industry: The case of AGBAR. Geoforum, 2014, Vol. 53, p. 11-20.

MÖNCKEBERG, O. El Saqueo de los Grupos Económicos al Estado Chileno. Santiago de Chile: Ediciones B, 2001.

NARANJO, G. Expansión metropolitan en el periurbano de Santiago. Implicancias territoriales en la Provincia de Chacabuco. En: De Mattos, C.; Hidalgo, R. (editores). Santiago de Chile. Movilidad espacial y Reconfiguración Metropolitana. Santiago: EURE Libros y Serie GEOlibros, 2007, p. 227249.

NICOLAS-ARTERO, C. Memorias de agua. Las organizaciones de usuarios frente a la escasez en la cuenca de Chicureo, Colina (1962-2015). Revista Tiempo Histórico, 2015, Vol. 6 Nº10, p. 87-107.

PFLIEGER, G. Historia de la universalización del acceso al agua y alcantarillado en Santiago de Chile (1970-1995). EURE, 2008, Vol 34 Nº103, p. 131-152.

PODUJE, I.; YAÑEZ, G. Planificando la ciudad virtual: megaproyectos urbanos estatales y Privados. Seminario Internacional Las regiones metropolitanas del Mercosur y México: entre la competitividad y la complementariedad. Buenos Aires: Programa de Investigación Internacional Grandes Regiones Metropolitanas del Mercosur y México, 2000.

RIVERA, R. Sectores altos de Santiago son los que tienen el mayor consumo de agua en Chile. El Mercurio, 27 de noviembre de 2011. Disponible en Internet: www.emol.com/noticias/econo$\mathrm{mia} / 2011 / 11 / 24 / 514225 / \mathrm{np}$-fds-sobre-los-1000-litros-de-agua-por-persona-son-consumidos-porhabitantes-de-sectores-altos-del-pais.html

ROMERO, H.; VÁSQUEZ, A. La Comodificación de los Territorios Urbanizables y la Degradación Ambiental en Santiago de Chile. Scripta Nova, 2005, Vol. 9 N¹94, p. 1 -68.

REIS, N. Coyotes, Concessions and Construction Companies: Illegal water markets and legally constructed water scarcity in Central Mexico. Water Alternatives, 2014, Vol. 7 N³, p. 542-560.

SALAZAR, A. La periurbanización en la recomposición de los espacios rurales metropolitanos: Santiago de Chile. En: De Mattos, C.; Hidalgo, R. (editores.). Santiago de Chile. Movilidad espacial y Reconfiguración Metropolitana. Santiago: EURE Libros y Serie GEOlibros, 2007, p. 207-225. 
SHATKIN, G. The City and the Bottom Line: Urban Megaprojects and the Privatization of Planning in Southeast Asia. Environment and Planning A, 2008, Vol. 40 N²2, p. 383-401.

SILVEIRA, M. L. Los territorios corporativos de la globalización. Geograficando, 2007, Vol. 3 №3, p. 13-26.

SWYNGEDOUW, E.; HEYNEN, N. C. Urban political ecology, justice and the politics of scale. Antipode, 2003, Vol. $35 \mathrm{~N}^{\circ} 5$, p. 898-918.

SWYNGEDOUW, E; KAIKA, M. Urban Political Ecology. Great Promises, Deadlock... and New Beginnings? Documents d'Analisi Geografica, 2014, Vol. 30 N³, p. 459-481.

WISSINK, B. Enclave urbanism in Mumbai: An Actor-Network-Theory analysis of urban (dis)connection. Geoforum, 2013, Vol. 47, p. 1-11.

ZIMMER, A. Urban Political Ecology. Theoretical concepts, challenges, and suggested future directions. Erdkunde, 2010, Vol. 64 N4, p. 343-354. 
